\title{
Congenital Radioulnar Synostosis, a case report
}

\author{
M Tantray, A Wani, G Kuchey, M Bhat, G Wali, S Sharma
}

\section{Citation}

M Tantray, A Wani, G Kuchey, M Bhat, G Wali, S Sharma. Congenital Radioulnar Synostosis, a case report. The Internet Journal of Orthopedic Surgery. 2008 Volume 15 Number 1.

\section{DOI: $\underline{10.5580 / 1298}$}

\section{Abstract}

\section{INTRODUCTION}

Congenital radioulnar synostosis is a congenital disorder involving radius and ulna, most commonly the proximal ends. The movements between radius and ulna are restricted and the forearm is fixed in varying degrees of pronation.It is mostly bilateral with familial predisposition (autosomal dominant) Wilkie has noted two types: In type 1 medullary canal of radius and ulna are joined with malformed head of radius which is fused with ulna for several centimeters. The radius is longer and its shaft arches anteriorly.In type 2 the radius is fairly normal and but its proximal end is dislocated either anteriorly or posteriorly and is fused with proximal ulna. This type is usually unilateral and is sometimes associated with deformities like supernumerary thumb; absence of thumb, syndactylism .The disorder may be associated with abnormalities of subcutaneous fascial tissues which may be short and abnormally directed. There is no definitive treatment to restore the movements at radioulnar joints; however osteotomy may be performed to bring the forearm into a more functional position especially if the condition is bilateral. Another study has shown the mobilisation operation by separation of synostosis and placement of faciocutaneous graft between the proximal radius and ulna. This is supplemented with proximal radial osteotomy to reduce the dislocated head of radius. These operations may benefit some patients by bringing the forearm into more functional position.

\section{CASE REPORT}

A 3 year old female patient presented to us with parents noticing that the child was unable to supinate both the forearms. There were no other symptoms associated with it. The child was born by normal vaginal delivery and was third in birth order. Other siblings were normal.
On clinical examination the child was unable to fully supinate both the forearms and had multiple constriction bands over both the forearms. The child's left forearm was pronated to a greater degree than the right as shown in fig.1.

\section{Figure 1}

Figure1: Clinical photograph of child showing constriction bands in bilateral forearm

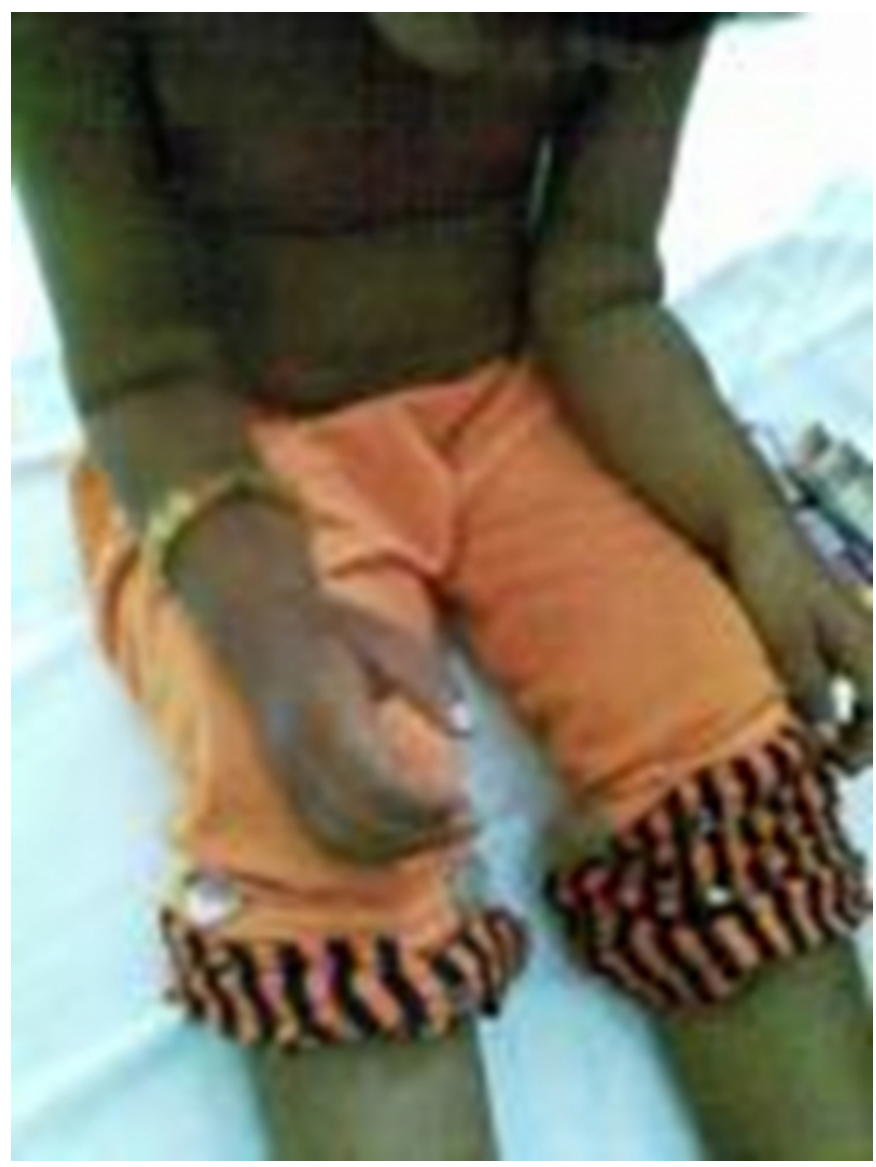

On attempted supination child's arms got adducted as a compensatory mechanism as shown in figure 2 . 


\section{Figure 2}

Figure 2: Clinical picture of the same child showing inability to fully supinate the forearms on attempted supination. Note child\&rsquo;s arms go into adduction on attempted supination.

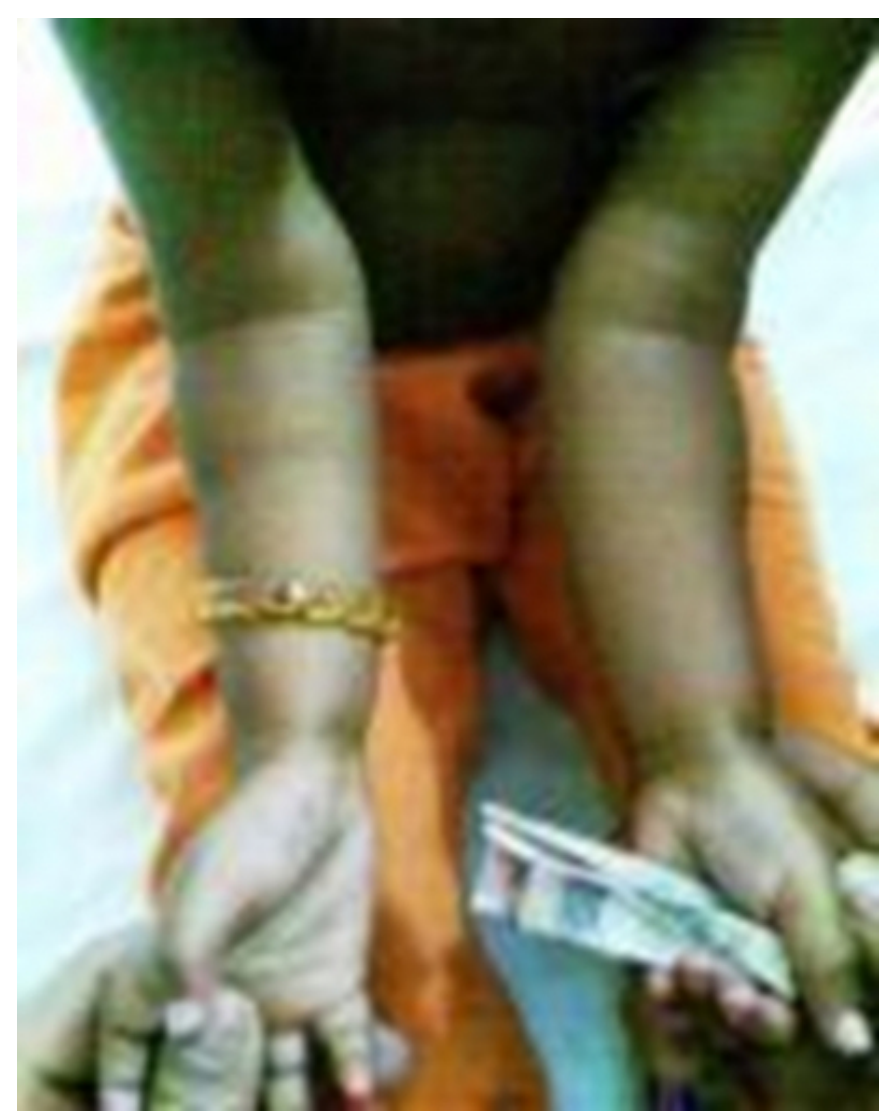

Range of motion at wrist and elbow were normal. The rest of the clinical examination was normal.

\section{ON RADIOLOGICAL EVALUATION}

On radiography there is fusion of proximal end of radius and ulna with posterior dislocation of radial head and normal development of radius bilaterally. There was no associated significant radiological abnormality.

\section{Figure 3}

Figure 3: Anteroposterior radiograph of right and left forearm showing bilateral proximal radioulnar synostosis. Note the posterior dislocation of radius proximally and the radius is normally developed

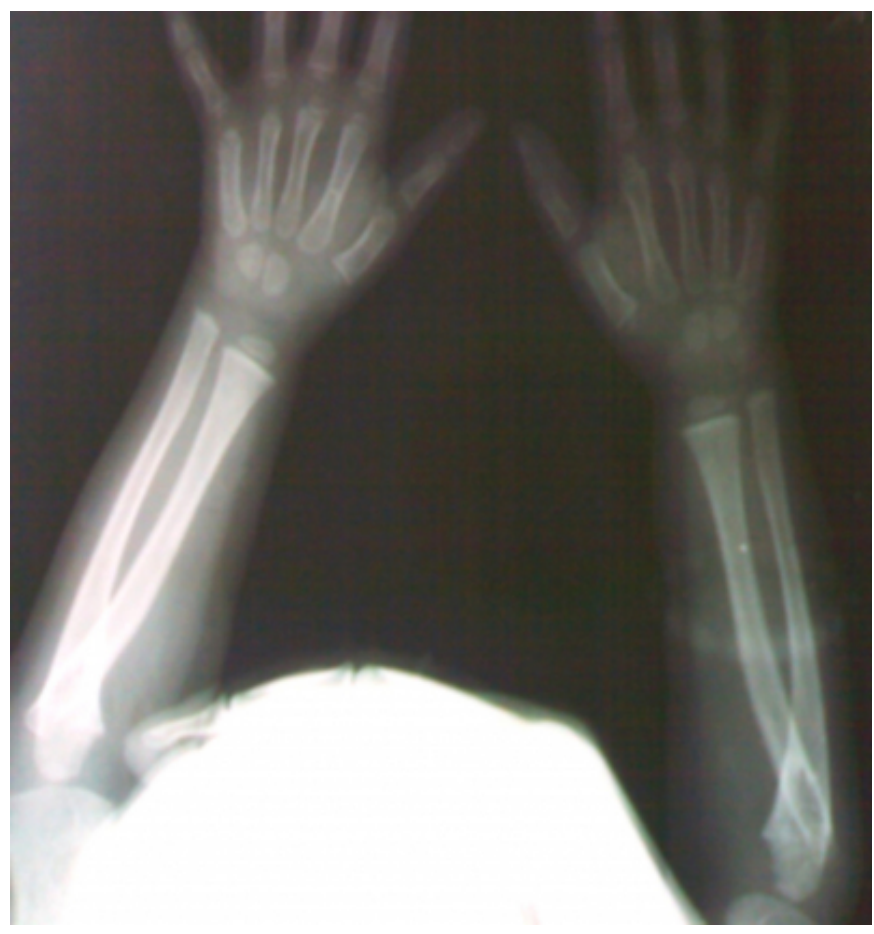

Childs parents were explained about the problem and were informed about the limited success of surgical management. The child was able to grip and hold bowl of food and was able to take meals unaided, there was not much of the functional impairment. Left forearm was pronated to greater degree than right; this was favorable as child could reach the orifices decreasing the degree of his handicap. The parents were counseled properly. The child is under our follow up and osteotomy has been kept optional in case of any functional impairment.

\section{References}

1. Bauer M johnsson k: Congenital radioulnar synostosis: Radiological characteristics and hand function case reports, Scand J plast reconstr surgery hand surg 22:251, 1988.

2. Dal Monte A, Andrisano A, Bungaro P, et al: Congenital proximal radio_ulnar synostosis: Clinical and anatomic features, Ital J orthop_ Traumatol 13:201, 1987.

3. Dalton JF 4th, Manske PR, Walter JC, et al: Ulnar nonunion after ostoclasis for rotational deformities of the forearm, J Hand surg 31A: 973, 2006.

4. Wilkie DPD: Congenital Radio_ulnar synostosis Br J Surg $1: 366,1913 \_1914$. 


\section{Author Information}

Mehraj Din Tantray, MBBS

Postgraduate scholar in orthopaedics, Government Medical College

\section{Ajaz Majeed Wani, MBBS}

Postgraduate scholar in orthopaedics, Government Medical College

\section{Gulzar Ahmad Kuchey}

Post graduate in orthopaedics, Government Medical College

\section{Masood Habib Bhat}

Post graduate in orthopaedics, Government Medical College

\section{G.R Wali Wali}

Postgraduate scholar in orthopaedics, Government Medical College

\section{Sudesh Sharma Sharma}

Professor in orthopaedic surgery, Government Medical College 